\title{
Differential response to gepirone but not to chlordiazepoxide in malnourished rats subjected to learned helplessness
}

\author{
L.M.M. Camargo ${ }^{1}$, A.B. Nascimento ${ }^{1}$ and S.S. Almeida ${ }^{2}$ \\ 1Departamento de Psicologia Geral e Análise do Comportamento, Universidade Estadual de Londrina, \\ Londrina, PR, Brasil, 'Laboratório de Nutrição e Comportamento, Departamento de Psicologia e \\ Educação, Faculdade de Filosofia, Ciências e Letras de Ribeirão Preto, Universidade de São Paulo, \\ Ribeirão Preto, SP, Brasil
}

Correspondence to: S.S. Almeida, Departamento de Psicologia e Educação, FFCLRP, USP, Av. Bandeirantes, 3900, 14040-901 Ribeirão Preto, SP, Brasil

Fax: +55-16-3602-4835. E-mail: sebasalm@usp.br

\begin{abstract}
The learned helplessness ( $\mathrm{LH})$ paradigm is characterized by learning deficits resulting from inescapable events. The aims of the present study were to determine if protein-calorie malnutrition (PCM) alters learning deficits induced by $\mathrm{LH}$ and if the neurochemical changes induced by malnutrition alter the reactivity to treatment with GABA-ergic and serotonergic drugs during LH. Well-nourished (W) and PCM Wistar rats (61 days old) were exposed or not to inescapable shocks (IS) and treated with gepirone (GEP, 0.0-7.5 mg/kg, intraperitoneally, $\mathrm{N}=128$ ) or chlordiazepoxide $(0.0-7.5 \mathrm{mg} / \mathrm{kg}$, intraperitoneally, $\mathrm{N}=128) 72 \mathrm{~h}$ later, 30 min before the test session (30 trials of escape learning). The results showed that rats exposed to IS had higher escape latency than non-exposed rats $(12.6 \pm 2.2$ vs $4.4 \pm 0.8 \mathrm{~s})$ and that malnutrition increased learning impairment produced by LH. GEP increased the escape latency of W animals exposed or non-exposed to IS, but did not affect the response of PCM animals, while chlordiazepoxide reduced the escape deficit of both W and PCM rats. The data suggest that PCM animals were more sensitive to the impairment produced by LH and that PCM led to neurochemical changes in the serotonergic system, resulting in hyporeactivity to the anxiogenic effects of GEP in the LH paradigm.
\end{abstract}

Key words: Protein-calorie malnutrition; Learned helplessness; Chlordiazepoxide; Gepirone; Rats

Research supported by FAPESP (No. 02/05674-5) and CNPq (Nos. 470415/2003-7 and 411029/2003-7). S.S. Almeida was the recipient of a research fellowship from CNPq (No. 351507/1996-5).

Received April 4, 2007. Accepted September 13, 2007

\section{INTRODUCTION}

Protein or protein-calorie malnutrition (PCM) early in life produces morphological, neurochemical and behavioral alterations in rats tested as adults $(1,2)$. Behavioral alterations following malnutrition cannot be attributed only to morphological and/or neurochemical changes in the central nervous system. Several lines of experimental evidence show that environmental changes concurrent with malnutrition procedures may explain, in part, the behavioral alterations observed in malnourished organisms (3-5). It has been shown that early protein malnutrition changes mother-pup and pup-pup interactions during lactation $(6,7)$, promoting a drastic reduction in social and environmental exploration early in life, a phenomenon described as "functional isolation" (8). Although there are no animal studies showing that the isolation from the environment produced by malnutrition leads to behavioral despair, a study on human malnutrition has reported that depressive symptoms, especially feelings of hopelessness, occur more often among mothers of malnourished children than among mothers of control children (9). The hopelessness feelings could be due to the absence of control on the part of the mothers of the environmental variables that lead to miserable living conditions and eventually to malnutrition. Thus, this uncontrollability of environmental variables may alter the behavior of the mothers 
and their interactions with the children, possibly producing long-lasting emotional alterations later in life in children.

In rats, it has been described that early protein malnutrition also produces changes in emotionality, especially in the reaction of the animals to aversive stimuli. It has been shown that malnutrition early in life produces increased reactivity to electric shocks (10) as well as increased inhibitory avoidance in procedures using painful stimuli (11-13). However, there are no reports in the literature about the effects of inescapable shocks (IS) on the behavior of malnourished animals. IS are extensively used in the classical model of learned helplessness (LH) (14). In this model, described as an experimental model of depression (15), animals previously exposed to IS present a subsequent impairment in the performance of an escape task $(16,17)$. Given the reports showing the participation of serotonergic and GABA-ergic neurotransmitter systems in the development, maintenance, prevention, and reversal of LH (18-21) and the changes in these neurotransmitter systems produced by early protein malnutrition $(1,22,23)$, it would be relevant to investigate $\mathrm{LH}$ in malnourished animals.

Thus, the main objective of the present study was to investigate the effects of early PCM and of acute treatment with serotonergic (gepirone) and benzodiazepine (chlordiazepoxide) drugs on the expression of escape deficit induced by the LH paradigm.

\section{MATERIAL AND METHODS Animals}

Male Wistar rats from the animal colony of the Londrina State University campus, Brazil, were used. On the day of birth each litter was culled to 6 male pups. During the lactation period (0-21 days of age), well-nourished (W) pups were fed by mothers maintained on an ad libitum commercial diet (Purina, Cascavél, PR, Brazil), and malnourished pups were fed by mothers receiving $40 \%$ of the amount of diet consumed by the ad libitum control group. The litters were housed in opaque plastic cages $(40 \times 30 \times 20 \mathrm{~cm})$. After weaning ( 22 days of age) the dams were removed from the cages and the pups of both groups were given free access to the diet up to the 60th day. The animals were kept on a 12$\mathrm{h}$ light/dark cycle with lights on at 7:00 am and room temperature kept at $23-25^{\circ} \mathrm{C}$. The experiment was conducted during the dark portion of the cycle.

\section{Apparatus}

During the training phase two shock stimulators (model M-EP01, Funbec, São Paulo, SP, Brazil) and four Skinner boxes (Funbec) were used. During the testing phase a 50 x 25 x 25-cm shuttle-box (Funbec) divided into two parts by a 5 -cm sliding door was used.

\section{Procedure}

At 61 days of age, $W$ rats and rats subjected to PCM were assigned to the IS or to the non-shock (NS) group, thereby generating 4 experimental groups for the LH paradigm: WIS (well-nourished, inescapable shock); WNS (wellnourished, non-shocked); MIS (malnourished, inescapable shock), and MNS (malnourished, non-shocked).

\section{Inescapable shock session}

At 61 days of age, rats of the WIS and MIS groups were placed individually in a Skinner box and exposed to 60 inescapable 8-s footshocks of $0.6 \mathrm{~mA}$. Shocks were delivered according to a variable time schedule, and the intershock interval averaged $60 \mathrm{~s}$. WNS and MNS rats were also placed in Skinner boxes, but no shock was delivered to them.

\section{Test session}

Seventy-two hours after the training session and 30 min before the test session rats received a single injection of gepirone, chlordiazepoxide, or vehicle ( $N=8$ for each group: WIS, WNS, MIS, and MNS). Thus, there were 128 rats in the gepirone group (64 of them well-nourished and 64 malnourished) and 128 rats in the chlordiazepoxide group (64 of them well-nourished and 64 malnourished). Rats were placed on side A of the shuttle-box (where the shocks were delivered), and could escape to side B (where no shocks were delivered) by jumping through the middle sliding door. The intensity of the shock was the same as in the training session. If the animal did not escape to side $B$, the shock was turned off after $30 \mathrm{~s}$ and the animal was removed by the experimenter and placed on side $B$ in which it remained for $30 \mathrm{~s}$ before being placed again on side A for the next trial. The test session consisted of 30 trials. The experiments reported in the present paper were performed in compliance with the recommendations of the Brazilian Society of Neuroscience and Behavior (SBNeC), which are based on the US National Institutes of Health Guide for Care and Use of Laboratory Animals.

\section{Drugs}

Gepirone $\mathrm{HCl}$ (Bristol-Myers, Wallingford, CT, USA) and chlordiazepoxide hydrochloride Psicosedin $^{\mathrm{TM}}$, Farmasa, São Paulo, SP, Brazil) were both dissolved in distilled water. Acute injections of vehicle (distilled water), gepirone $(2.5,5.0$, or $7.5 \mathrm{mg} / \mathrm{kg})$ or chlordiazepoxide $(2.5$, $5.0,7.5 \mathrm{mg} / \mathrm{kg}$ ) were administered intraperitoneally (ip) in a volume of $1 \mathrm{~mL} / \mathrm{kg}, 30 \mathrm{~min}$ before the test session.

\section{Data analysis}

Escape latency was analyzed by three-way (diet condi- 
tion $x$ shock procedure $x$ dose of the drug) analysis of variance (ANOVA) and rat body weight was analyzed by two-way ANOVA (diet condition $\mathrm{x}$ age). Post hoc comparisons were made using the Newman-Keuls test. The level of significance was set at $P<0.05$ in all analyses.

\section{RESULTS}

\section{Body weight}

The body weight of the animals (Figure 1) was affected by diet restriction, with $\mathrm{W}$ animals being heavier than PCM animals as indicated by a significant effect of diet $(F(1,179)$ $=448.8, \mathrm{P}<0.001)$. Animals of all groups significantly increased their body weights across age $(F(8,179)=760.5$, $P<0.001)$. However, $W$ animals had a greater increase compared with PCM animals as indicated by a significant diet $x$ age interaction $(F(8,179)=26.5, P<0.001)$.

\section{Behavioral measures}

Gepirone. As shown in Figure 2, there was a significant effect of procedure $(F(1,674)=193.8, P<0.001)$, with IS animals presenting higher escape latencies compared with NS animals. There was also a significant effect of dose $(F(3,674), P<0.001)$, with post hoc analysis indicating a significant increase of escape latency at the dose of $5 \mathrm{mg} / \mathrm{kg}$ compared with saline $(P<0.05)$. However, this increase in escape latency was statistically significant only in $\mathrm{W}$ animals compared with PCM animals, leading to a significant diet $\mathrm{x}$ dose interaction $(\mathrm{F}(3,674)=18.2, \mathrm{P}<$ 0.001).

Chlordiazepoxide. As shown in Figure 3, there was a significant effect of procedure $(F(1,673)=198.5, P<$ 0.001 ), with IS animals presenting higher escape latencies compared with NS animals. There was also a significant

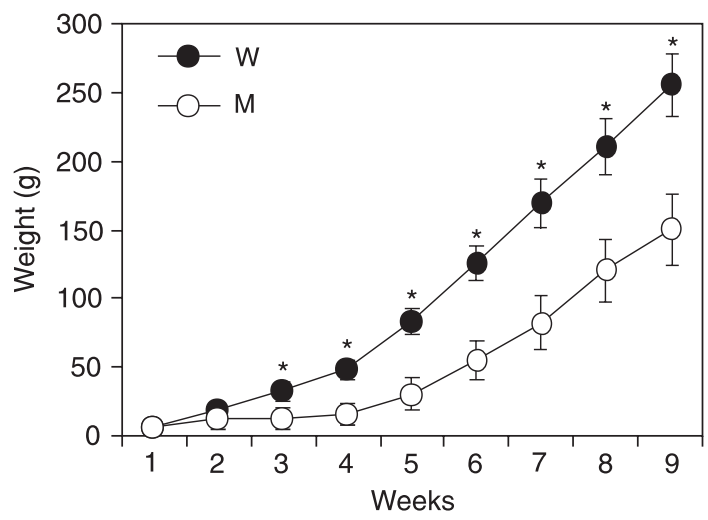

Figure 1. Body weight of well-nourished (W) and malnourished (M) animals from birth to age of testing. Data are reported as means \pm SEM for $N=18$ animals for each condition. ${ }^{*} \mathrm{P}<0.05$ compared with malnourished animals (Newman-Keuls test).

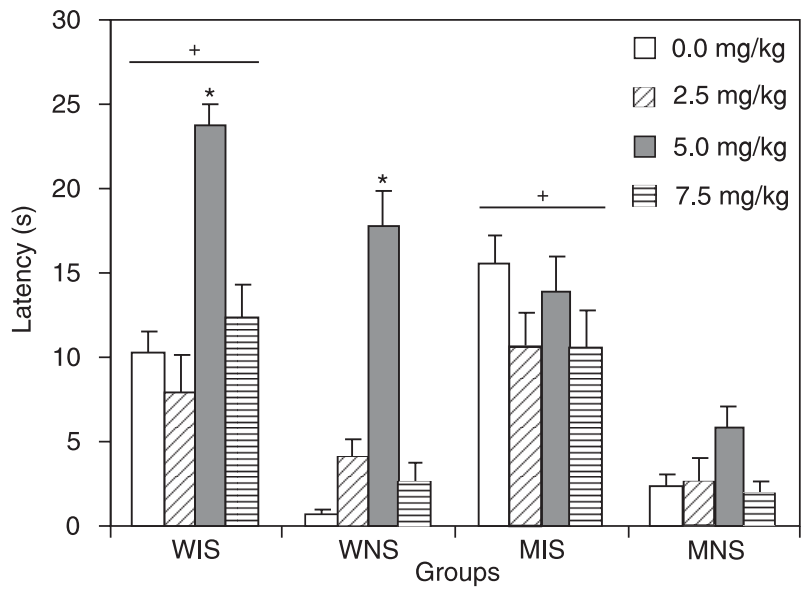

Figure 2. Latency of the escape response of well-nourished and malnourished animals after acute treatment with gepirone. Data are reported as means \pm SEM for $N=8$ animals for each condition. WIS = well-nourished animals exposed to inescapable shocks; WNS = well-nourished animals not exposed to inescapable shocks; MIS = malnourished animals exposed to inescapable shocks; MNS = malnourished animals not exposed to inescapable shocks. ${ }^{*} \mathrm{P}<0.05$ compared with $0.0 \mathrm{mg} / \mathrm{kg}$ within the same group and ${ }^{+} \mathrm{P}<0.05$ compared with non-shocked animals (Newman-Keuls test).

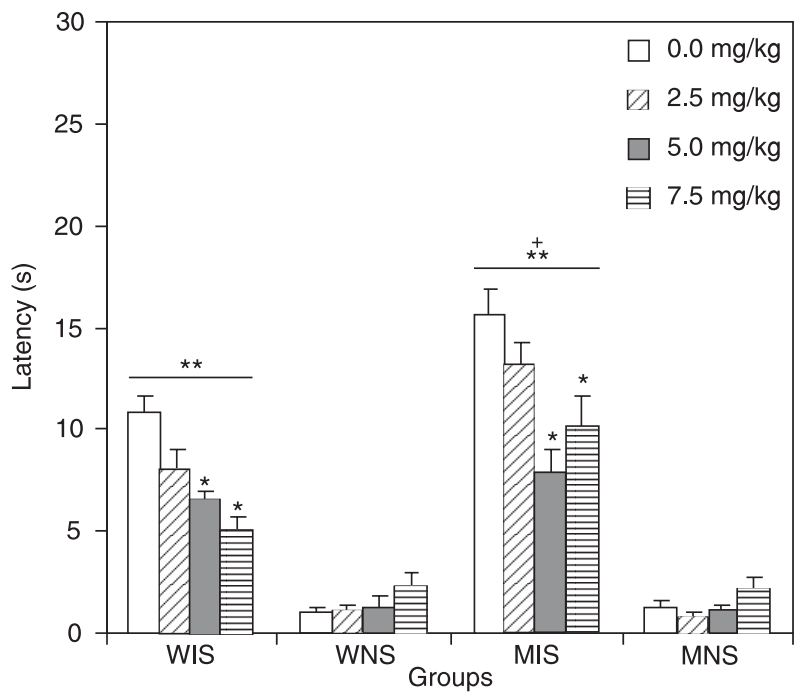

Figure 3. Latency of the escape response of well-nourished and malnourished animals after acute treatment with chlordiazepoxide. Data are reported as means \pm SEM for $N=8$ animals for each condition. WIS = well-nourished animals exposed to inescapable shocks; WNS $=$ well-nourished animals not exposed to inescapable shocks; MIS = malnourished animals exposed to inescapable shocks; MNS = malnourished animals not exposed to inescapable shocks. ${ }^{*} \mathrm{P}<0.05$ compared with $0.0 \mathrm{mg} / \mathrm{kg}$ within the same group, ${ }^{* *} \mathrm{P}<0.05$ compared with non-shocked animals, and ${ }^{+} \mathrm{P}<0.05$ compared with WIS animals (NewmanKeuls test). 
effect of dose $(F(3,674), P<0.001)$, with post hoc analysis indicating a significant decrease of escape latency at the doses of 5.0 and $7.5 \mathrm{mg} / \mathrm{kg}$ as compared with saline $(\mathrm{P}<$ 0.05). In addition, ANOVA showed a significant effect of diet $(F(1,673)=15.8, P<0.001)$, with PCM animals presenting higher escape latencies than $\mathrm{W}$ animals. Finally, there was also a significant diet $x$ shock procedure interaction $(F(1,673)=8.62, P<0.01)$ and a significant shock procedure $x$ drug dose interaction $(F(3,673)=8.17, P<$ 0.001). Post hoc analysis showed that the diet $x$ shock interaction was due to greater increases $(P<0.05)$ in the escape latency for PCM animals exposed to IS, while the shock procedure $x$ drug dose interaction was due to a significant decrease in escape latency in IS compared with no effects in NS animals $(P<0.05)$ following pharmacological treatment.

\section{DISCUSSION}

The nutritional manipulation imposed on the dams directly affected pup body weight. Early PCM produced a significant decrease in the animal's body weight, a wellestablished result also reported in previous studies $(24,25)$.

The behavioral data in the LH test showed that animals exposed to IS present longer escape latencies compared with animals not exposed to IS, in agreement with previous literature data (17).

Moreover, early PCM increased the effects of the IS as demonstrated by longer escape latencies in PCM animals compared with $\mathrm{W}$ animals in the group treated with chlordiazepoxide, indicating that the nutritional insult increased the impairment of escape learning following the helplessness procedure. Although a similar result could be observed in the gepirone group (i.e., longer latencies in PCM rats compared with $\mathrm{W}$ rats), it was not possible to demonstrate a statistical effect since the strong response of $\mathrm{W}$ animals to the $5.0 \mathrm{mg} / \mathrm{kg}$ dose precluded the finding of a significant effect of diet. This result can be interpreted not only as an increased learning impairment produced by the experience of inescapable shock, but also as a lower shock threshold in malnourished animals. A lower shock threshold produced by early malnutrition has already been described (10). However, increased impairment of learning produced by the uncontrollability of the shocks in PCM animals appears to be a more plausible explanation since no differences due to diet were observed in the reactivity to shock on escape latencies of the groups not exposed to IS before escape learning. If this apparent increased sensitivity of PCM animals to inescapable painful aversive stimuli is due to environmental changes produced by early malnutrition (i.e., hopelessness of malnourished mothers during lactation), similar results can be expected in other experi- mental models of behavioral despair. Since there are reports in the literature showing that early malnutrition is a biological risk factor for further affective disorders, including depression $(26,27)$, it would be interesting to investigate the effects of early malnutrition on behavioral despair models.

The significant increase in escape latency after acute gepirone treatment $(5.0 \mathrm{mg} / \mathrm{kg})$ in the present study agrees with previously reported data comparing an anxiolytic profile after chronic treatment (28). It has been reported that the $5-\mathrm{HT}_{1 \mathrm{~A}}$ receptor subtype is the primary site of action of the azaperone class of drugs such as buspirone, ipsapirone and gepirone (28). These receptor subtypes are present on the soma and dendrites of 5-HT neurons and on postsynaptic neurons in the brain (hippocampus, septum, neocortex, amygdala, and hypothalamus) and on the spinal cord (29). Thus, the present results showing anxiogenic effects of acute treatment compared with an anxiolytic effect of chronic treatment (28) support the assumption that an anxiolytic effect of drugs acting on $5-\mathrm{HT}_{1 \mathrm{~A}}$ receptors is only possible by the sustained presence of 5$\mathrm{HT}_{1 \mathrm{~A}}$ agonists (30). The stronger effect of gepirone at the dose of $5.0 \mathrm{mg} / \mathrm{kg}$ and the lower effect with 2.5 and $7.5 \mathrm{mg} /$ $\mathrm{kg}$ is an example of what is known as a non-monotonic dose-response curve. In this condition the curves are shaped like inverted U's with the greatest response in intermediate ranges. In addition, the effect of gepirone could not be attributed to effects on locomotor activity since this drug did not alter locomotion in models of anxiety (28). The absence of gepirone effects on the malnourished animals is a pharmacological evidence that early protein malnutrition affects the serotonergic neurotransmitter system, especially $5-\mathrm{HT}_{1 \mathrm{~A}}$ receptor subtypes. According to this interpretation, it has been shown that $5-\mathrm{HT}_{1 \mathrm{~A}}$ receptors assayed with $(3 \mathrm{H}) 8-\mathrm{OH}-\mathrm{DPAT}$ were decreased by $20 \%$ in the hippocampal CA3 subfield of early protein-malnourished rats (31). Moreover, it has also been reported that the sensitivity of $5-\mathrm{HT}$ receptors stimulated with $8-\mathrm{OH}$ DPAT is increased in well-nourished animals exposed to chronic stress compared with no effect in malnourished animals (32), indicating a lack of adaptive changes at serotonergic sites following early malnutrition. In addition, hyporeactivity to the effects of serotonergic drugs after early protein malnutrition has also been reported, showing that malnourished animals have a lower response to ipsapirone in the hypertonic saline ingestion test (33) and in the elevated plus-maze test (34), indicating that the nutritional insult causes long-term alteration in the serotonergic neurotransmitter system.

Treatment with chlordiazepoxide produced a significant decrease in escape latency only in the group of IS 
animals, indicating that this drug reversed, in part, the learning impairment produced by IS, especially with the doses of 5.0 and $7.5 \mathrm{mg} / \mathrm{kg}$. The reversal of this impairment after treatment with the $\mathrm{GABA}_{\mathrm{A}}$ receptor agonists muscimol and fengabine has also been reported (35), suggesting a participation of the GABA-benzodiazepine system in the LH model (21). In agreement with these results are the reports showing that GABA microinjected into the hippocampus also reverses $\mathrm{LH}$ when injected after IS (36), while the $\mathrm{GABA}_{\mathrm{A}}$ receptor antagonist (bicuculline) injected into the same region induced LH (37). Early PCM did not change the reactivity of the animals to the effects of chlordiazepoxide in the LH model. This result contrasts with several reports showing hyporeactivity of malnourished animals to treatment with benzodiazepines (for a review, see Ref. 1). However, the great majority of these reports were obtained in behavioral models without the use of painful aversive stimuli or at least using controllable shock procedures. Thus, it is possible that the controllability of the aversive stimulus can play an important role in the response of malnourished organisms to benzodiazepine anxiolytic drugs.

Finally, since the drugs were administered before the behavioral test it is possible that the behavioral changes observed were due to the action of these drugs on the expression of escape behavior rather than on processes of learning and memory per se. Previous data from our group using drugs of the same class in different experimental models (elevated plus-maze and hypertonic saline ingestion) have suggested a possible involvement of the drugs in the expression of the behavior rather than in the ability of the animals to learn a task $(33,34)$. Future studies using experimental models of painless stimuli such as the forced swimming test could definitely contribute to elucidate the effects of drugs acting on the serotonergic and GABAergic neurotransmitter systems of early malnourished animals. The use of a painless stimulus prevents possible confounding factors due to the well-described lower shock threshold observed in malnourished animals (10).

\section{REFERENCES}

1. Almeida SS, Tonkiss J, Galler JR. Malnutrition and reactivity to drugs acting in the central nervous system. Neurosci Biobehav Rev 1996; 20: 389-402.

2. Morgane PJ, Austin-LaFrance R, Bronzino J, Tonkiss J, Díaz-Cintra S, Cintra L, et al. Prenatal malnutrition and development of the brain. Neurosci Biobehav Rev 1993; 17: 91-128.

3. Levine S, Weiner SG. Malnutrition and early environmental experience: possible interactive effects on later behavior. In: Walsh RN, Greenough WT (Editors), Environment as therapy for brain dysfunction. New York: Plenum Press; 1976.
4. Levitsky DA, Barnes RH. Nutritional and environmental interactions in the behavioral development of the rat: longterm effects. Science 1972; 176: 68-71.

5. Santucci LB, Daud MM, Almeida SS, de Oliveira LM. Effects of early protein malnutrition and environmental stimulation upon the reactivity to diazepam in two animal models of anxiety. Pharmacol Biochem Behav 1994; 49: 393-398.

6. Massaro TF, Levitsky DA, Barnes RH. Protein malnutrition induced during gestation: its effect on pup development and maternal behavior. Dev Psychobiol 1977; 10: 339-345.

7. Riul TR, Carvalho AF, Almeida PS, De-Oliveira LM, Almeida SS. Ethological analysis of mother-pup interactions and other behavioral reactions in rats: effects of malnutrition and tactile stimulation of the pups. Braz J Med Biol Res 1999; 32: 975-983.

8. Levitsky DA, Massaro TF, Barnes RH. Maternal malnutrition and the neonatal environment. Fed Proc 1975; 34: 1583-1586.

9. Salt P, Galler JR, Ramsey FC. The influence of early malnutrition on subsequent behavioral development. VII. The effects on maternal depressive symptoms. J Dev Behav Pediatr 1988; 9: 1-5.

10. Smart JL, Whatson TS, Dobbing J. Thresholds of response to electric shock in previously undernourished rats. $\mathrm{Br} J$ Nutr 1975; 34: 511-516.

11. Lynch A. Passive avoidance behavior and response thresholds in adult male rats after early postnatal undernutrition. Physiol Behav 1976; 16: 27-32.

12. Almeida SS, De-Oliveira LM, Bichuette MZ, Graeff FG. Early malnutrition alters the effect of chlordiazepoxide on inhibitory avoidance. Braz J Med Biol Res 1988; 21: 1033-1036.

13. Almeida SS, Soares EG, Bichuette MZ, Graeff FG, de Oliveira $L M$. Effects of early postnatal malnutrition and chlordiazepoxide on experimental aversive situations. Physiol Behav 1992; 51: 1195-1199.

14. Hunziker MHL. O desamparo aprendido revisitado: estudos com animais. Psicol Teor Pesqui 2005; 21: 131-139.

15. Willner $P$. The validity of animal models of depression. Psychopharmacology 1984; 83: 1-16.

16. Seligman ME, Maier SF. Failure to escape traumatic shock. $J$ Exp Psychol 1967; 74: 1-9.

17. Maier SF, Seligman MEP. Learned helplessness: Theory and evidence. J Exp Psychol Gen 1976; 105: 3-46.

18. Graeff EO, Hunziker MH, Graeff FG. Effects of ipsapirone and BAY R 1531 on learned helplessness. Braz J Med Biol Res 1989; 22: 1141-1144.

19. Maier SF, Grahn RE, Kalman BA, Sutton LC, Wiertelak EP, Watkins LR. The role of the amygdala and dorsal raphe nucleus in mediating the behavioral consequences of inescapable shock. Behav Neurosci 1993; 107: 377-388.

20. Petty F, Kramer G, Wilson L, Jordan S. In vivo serotonin release and learned helplessness. Psychiatry Res 1994; 52: 285-293.

21. Kram ML, Kramer GL, Steciuk M, Ronan PJ, Petty F. Effects of learned helplessness on brain GABA receptors. Neurosci Res 2000; 38: 193-198.

22. Del Angel-Meza AR, Ramirez-Cortes L, Adame-Gonzalez IG, Gonzalez Burgos I, Beas-Zarate C. Cerebral GABA release and GAD activity in protein- and tryptophan-restricted rats during development. Int J Dev Neurosci 2002; 20: 47-54. 
23. Morgane PJ, Mokler DJ, Galler JR. Effects of prenatal protein malnutrition on the hippocampal formation. Neurosci Biobehav Rev 2002; 26: 471-483.

24. Clarke KA, Parker AJ, Smart JL. Analysis of walking locomotion in adult female rats undernourished as sucklings. Physiol Behav 1992; 52: 823-826.

25. Lago ES, Teodosio NR, Araujo CR, Azevedo MC, Pessoa DC, Campos FA, et al. Rat models of protein and proteinenergy malnutrition. Int J Vitam Nutr Res 1993; 63: 52-56.

26. Casper RC. Nutrients, neurodevelopment, and mood. Curr Psychiatry Rep 2004; 6: 425-429.

27. Tiemeier $\mathrm{H}$. Biological risk factors for late life depression. Eur J Epidemiol 2003; 18: 745-750.

28. Silva RC, Brandão ML. Acute and chronic effects of gepirone and fluoxetine in rats tested in the elevated plus-maze: an ethological analysis. Pharmacol Biochem Behav 2000; 65: 209-216.

29. Blier $\mathrm{P}$, Ward NM. Is there a role for $5-\mathrm{HT} 1 \mathrm{~A}$ agonists in the treatment of depression? Biol Psychiatry 2003; 53: 193203.

30. Blier $\mathrm{P}$, de Montigny $\mathrm{C}$. Modification of $5-\mathrm{HT}$ neuron properties by sustained administration of the 5-HT1A agonist gepirone: electrophysiological studies in the rat brain. Synapse 1987; 1: 470-480.

31. Blatt GJ, Chen JC, Rosene DL, Volicer L, Galler JR. Prenatal protein malnutrition effects on the serotonergic system in the hippocampal formation: an immunocytochemical, ligand binding, and neurochemical study. Brain Res Bull 1994; 34: 507-518.

32. Keller EA, Cancela LM, Molina VA, Orsingher OA. Lack of adaptive changes in 5-HT sites in perinatally undernourished rats after chronic stress: opioid influence. Pharmacol Biochem Behav 1994; 47: 789-793.

33. Almeida SS, de Oliveira LM, Graeff FG. Decreased reactivity to anxiolytics caused by early protein malnutrition in rats. Pharmacol Biochem Behav 1990; 36: 997-1000.

34. Almeida SS, de Oliveira LM, Graeff FG. Early life protein malnutrition changes exploration of the elevated plus-maze and reactivity to anxiolytics. Psychopharmacology 1991; 103: 513-518.

35. Lloyd KG, Zivkovic B, Sanger D, Depoortere H, Bartholini G. Fengabine, a novel antidepressant GABAergic agent. I. Activity in models for antidepressant drugs and psychopharmacological profile. J Pharmacol Exp Ther 1987; 241: 245-250.

36. Sherman AD, Petty F. Neurochemical basis of the action of antidepressants on learned helplessness. Behav Neural Biol 1980; 30: 119-134.

37. Petty F, Sherman AD. GABAergic modulation of learned helplessness. Pharmacol Biochem Behav 1981; 15: 567570. 